\title{
Identidades femininas e educación literaria: análise crítica das coleccións coeducativas para a infancia e a mocidade
}

\author{
Feminine Identity and Education through Literature: Critical Analysis \\ on Coeducational Collections for Children and Young People
}

\author{
Montse Pena Presas \\ Universidade de Santiago de Compostela \\ Departamento de Didáctica, Lingua e Literatura e das Ciencias Sociais \\ montserrat.pena@usc.es
}

[recibido 21/10/2014, aceptado 27/01/2015]

\begin{abstract}
Se ve en los museos, en las viejas pinturas, retratos de niña: angostos escarpines, recias faldas de terciopelo, el talle aprisionado en un corsé, ceñida la garganta en prietas cintas y el empechado sombrero aplastándoles la cabeza. Y collares, sortijas, brazaletes, broches... ¡Cómo sufrirían! Quisiéramos libertarlas, darles ropas flexibles y leves, adecuadas a su tierno cuerpo; como quisiéramos libertar a esos hombrecillos metidos en su coraza, metidos en su correaje y hundidos en sus botas, quienes, pese a su actitud heroica, tienen un aire ridiculo y desgraciado. Si durante siglos no se pensó siquiera en dotar a los niños de trajes adecuados, ¿cómo se pensaría en brindarles buenos libros?
\end{abstract}

(Paul Hazard, Los niños, los libros y los hombres)

\section{RESUMO}

Nos últimos anos o sistema literario galego asistiu ao xurdimento de diferentes coleccións coeducativas para o público infantoxuvenil que naceron, na súa meirande parte, ao abeiro de iniciativas institucionais. Este artigo pretende tanto contextualizalas - dando a coñecer os seus precedentes-, como analizalas dende o punto de vista da educación literaria e dende a perspectiva das diferentes identidades femininas que amosan.

PALABRAS CHAVE: Colección coeducativa, educación literaria, feminismo, identidade feminina, literatura infantil.

\section{RESUMEN}

En los últimos años, el sistema literario gallego asistió a la aparición de diferentes coleccións coeducativas para el público infantojuvenil que nacieron al amparo, en su mayor parte, de inciativas institucionales. Este artículo pretende tanto contextualizarlas -dando a conocer sus precedentes-, como analizarlas desde el punto de vista de la educación literaria y desde la perspectiva de las diferentes identidades femeninas que muestran.

PALABRAS CLAVE: Colección coeducativa, educación literaria, feminismo, identidade feminina, literatura infantil.

\begin{abstract}
During the last few years, the Galician literature system has witnessed the appearance of many different coeducation collections for children and young people that were promoted by institutional initiatives. The aim of this article is to contextualize them - revealing their precedents- as well as analysing them from a literature education point of view and from the perspective of the different feminine identities included in these collections.
\end{abstract}

KEY WORDS: Coeducation collection, literature education, feminism, feminine identity, children's literature.

Pena Presas, M. (2015): "Identidades femininas e educación literaria: análise crítica das coleccións coeducativas para a infancia e a mocidade”, Madrygal (Madr.), 18, Núm. Especial: 367-375.

SUMARIO: 1. Introdución: sobre o termo "colección coeducativa". 2. Contextualización: a orixe das coleccións a prol da coeducación. 3. Os precedentes das coleccións coeducativas. 3.1. A colección "A favor de las niñas". 3.2. Algunhas tentativas de material coeducativo en lingua galega. 4. As novas coleccións coeducativas: "Contos da igualdade", "Lila lilaina" e "A igualdade conta". 4.1. Consideracións dende o punto de vista da educación literaria. 4.2. Consideracións dende o punto de vista da identidade feminina. 5. A xeito de conclusión. 6. Referencias bibliográficas. 


\section{INTRODUCIÓN: SOBRE O TERMO "COLECCIÓN COEDUCATIVA"}

O título deste artigo é o suficientemente específico como para que sexa necesario, antes de comezar, facer certas aclaracións que permitan ás lectoras e lectores do mesmo ter unha idea precisa do que van atopar nas vindeiras páxinas. En primeiro lugar, cómpre esclarecer o sintagma "colección coeducativa", sobre o que xirará boa parte do aquí debullado. Co termo "colección coeducativa" alúdese a unha serie de obras publicadas baixo un nome propio común cunhas características semellantes e idéntico formato, cuxo fin principal é promover a igualdade entre os xéneros dende a literatura infantil.

Ademais, nelas poténcianse outros valores como a tolerancia, o respecto ou a valía da diferenza. Igualmente, no contexto en que se empregará o sintagma, fará alusión a coleccións que non supuxeron novidades fundamentais no sistema literario galego ${ }^{1}$, que contaron cun apoio institucional explícito -agás no caso de "Lila Lilaina" - e que saíron do prelo xa no século XXI.

Dado que habitualmente as coleccións coeducativas son percibidas polas mediadoras e mediadores como materiais que cómpre potenciar dende as aulas e/ou a través das bibliotecas, esta achega márcase como obxectivos principais: difundir os seus precedentes, dar a coñecer as existentes en galego e analizalas dende a perspectiva da educación literaria e das identidades femininas que amosan. Isto permitirá tanto romper certos tópicos sobre as mesmas, coma fornecer ao ensinante ou facilitador da lectura de ferramentas precisas para realizar a elección das obras infantís con que traballa.

\section{CONTEXTUALIZACIÓN: A ORIXE DAS COLECCIÓNS A PROL DA CO- EDUCACIÓN}

Para situar a orixe das coleccións coeducativas, débese ter en conta un duplo contexto: o que deu lugar á eclosión dunha literatura infantil en lingua galega e o que ten que ver coa evolución das reivindicacións do movemento feminista referidas á educación. Comezando polo primeiro, hai que aludir ao establecemento das leis ${ }^{3}$ que posibilitaron que o galego fose materia de ensino e que sustentaron a conformación dun sistema editorial sólido, a través do cal a literatura infantoxuvenil (LIX) na lingua do país experimentou unha rápida evolución. Esta transformación coincidiu temporalmente coas reivindicacións que, dende diferentes instancias críticas, pero maiormente dende o feminismo e dende algúns sectores dos movementos de renovación pedagóxica influenciados polas ideas a prol da igualdade, se estaban a facer para que as autoras e autores incorporasen máis personaxes femininos nas súas obras. A literatura galega dirixida a infancia e a mocidade sumou esta reivindicación dende diferentes perspectivas (a construcción de obras marcadamente feministas, a elaboración doutras onde se diversificaban o rol das protagonistas, o posicionamento das personaxes femininas en diferentes subxéneros narrativos...), especialmente grazas á implicación de diferentes autoras, como Xohana Torres, María Xosé Queizán ou Marilar Aleixandre e de certos autores, como Agustín Fernández Paz, que durante os anos 80 e principios dos 90 , foron os alicerces dende os que se construíu unha LIX máis igualitaria. Non obstante, as súas narrativas sempre conviviron con outras de carácter máis convencional, onde os estereotipos do masculino e do feminino seguían

\footnotetext{
${ }^{1}$ Isto débese a que existen precedentes claros que se enunciarán debidamente.

2 Polo menos, nin pola autoría nin polos paratextos formais existe ningún elemento que faga pensar en que ese apoio institucional existise.

${ }^{3}$ Refírome, en concreto, ao Decreto de Bilingüismo de 1979, que propiciou que a lingua galega fose materia de ensino e á Lei de Normalización Lingüística de 1983, que supuxo a introdución do galego nas aulas como idioma vehicular.
} 
a funcionar, tal e como acontece na actualidade. Téñase en conta que, analizadas as ficcións que se deron ao prelo orixinalmente en galego na década que abala entre 1975 e 1985, época en que as creadoras citadas comezaron a súa andaina na LIX, compróbase que tan só un $26{ }^{\prime} 53 \%$ dos personaxes protagónicos eran mulleres (Pena Presas 2012: 108).

No contexto de finais da década de 80 , había unha grande cantidade de mestras militantes ou influenciadas polo movemento feminista, que se ocupaban de traballar nas súas aulas con diferentes tipos de materiais coeducativos, entre os que estaba -en ocasións- a literatura infantoxuvenil. Elas tamén foron as primeiras que denunciaron a discriminación presente en moitas narracións para a infancia e a adolescencia. Bo exemplo disto é o colectivo de mestras "A favor de las niñas"4, que funcionou aproximadamente entre 1980 e 1988 en diferentes centros de Madrid, e que elaborou dende contos que deixaban en evidencia o papel que a literatura lles reserva ás mulleres (Gastaudi, 1983) ata bibliografías coeducativas (Colectivo Escuela no sexista, 1984), por poñer tan só exemplo de algúns dos seus materiais éditos e difundidos en revistas ben coñecidas. Neste sentido, cómpre resaltar que neste tempo, a abordaxe do sexismo na literatura infantil e xuvenil importa na medida en que importa a denuncia do sexismo na educación. As letras infantoxuvenís eran percibidas polas feministas como un elemento máis para acadar a desexada escola coeducativa efectiva.

Non obstante, tamén nesta etapa, o movemento feminista entrara nun proceso de cambio. Tras as reivindicacións de carácter máis social de finais dos 70, comezaran a xurdir novas formas de feminismo, para mudar cara a un perfil máis institucional -cuxo comezo se adoita situar en 1983, cando se funda o Instituto de la Mujer, por aquel entón dependente do Ministerio de Cultura- ou académico $^{5}$ (Folguera 2007: 178-179). Esta situación paseniñamente foi facilitando que algunhas militantes do movemento acadasen presenza nas institucións (cando menos nestes primeiros anos) creadas para tal fin. Co decorrer temporal e co efecto en cadea provocado pola constitución do Instituto de la Mujer, esta reconceptualización do feminismo e/ou a súa pegada en organismos oficiais, chega tamén a Galicia. Así, en 1989 créase o Servizo Galego de Promoción de Igualdade do Home e da Muller $^{6}$, que -fóra de que se poidan cuestionar ou non moitas das súas actuacións- serviu como marco dende o que pular por determinadas iniciativas vencelladas ao eido da educación -como as diferentes guías de literatura infantil e xuvenil non discriminatoria, con 3 entregas diferentes ata o momento.

\section{OS PRECEDENTES DAS COLEC- CIÓNS COEDUCATIVAS}

\subsection{A COLECCIÓN "A FAVOR DE LAS NIÑAS"}

Durante os anos 80 e principios dos 90, non existiron coleccións coeducativas institucionalizadas (é dicir, impulsadas por parte de algún organismo público ou dende o mundo académico). Porén, si houbo unha serie de libros, de iniciativa privada, cuxo obxectivo principal era crear narracións onde as mulleres tivesen un papel protagónico afastado das imaxes máis tradicionais de esposas, nais ou nenas pasivas. Dita colección tiña a súa orixe na editora homónima "Dalla parte della

\footnotetext{
${ }^{4}$ Esta é a denominación con que asinaban algunhas das súas últimas colaboracións, se ben é certo que a alternan con outras como "Escuela no sexista", "Escuela y roles sexuales" ou coa variante "Por una escuela a favor de las niñas", como se verá nalgún dos materiais citados.

${ }^{5}$ Por aquel entón comezan tamén a proliferar os seminarios, centros ou áreas dedicados ao estudo de cuestións vencelladas ás mulleres, como o Instituto de Estudios de la Mujer da Universidad Autónoma de Madrid, creado en 1979, ou o DUODA, Centre d'Investigació de Dones da Universitat de Barcelona, fundado en 1982.

${ }^{6}$ Logo chamado Servizo Galego de Igualdade.
} 
bambina" creada por Adela Turín en Milán en 1975, que entre a súa fundación e 1980 publicou máis de vinte contos que eliminaban roles tradicionais e prexuízos sexistas. As súas creadoras eran a propia Turín (responsable do texto) e Nellia Bosnia (ilustradora). No mercado estatal $^{7}$, a colección apareceu en 1976 da man da editorial Lumen baixo o nome "A favor de las niñas".

Porén, a publicación das narracións trouxo tamén non pouca controversia. Por un lado, supuxo para moitos unha mera inversión de roles que unicamente traía consigo a desvalorización de nenos e homes. Neste sentido, xa no seu tempo, os textos de "A favor de las niñas" foron considerados radicais e sexistas -no sentido inverso- por bastantes sectores, pois neles "las hembras son listas y dinámicas y los machos tontos y vanidosos" (Armonía Rodríguez 1977: 37). Este radicalismo propiciou que mesmo sectores implicados na coeducación ${ }^{9}$ considerasen estas ficcións como literatura de segunda pola súa grande carga ideolóxica. Na mesma liña se manifestaron Barrios e Zegors (1980, apud Gárate 1997: 12), que tras analizar a colección, observaron como nela os caracteres masculinos son incapaces de coidar a relación de parella, mentres as mulleres acaban de fuxir da mesma, moitas das veces para agruparse, e como resultado dese proceso, acaban liberándose.

A formación dun estereotipo novo, neste caso masculino, propicia que ambos autores se pregunten ironicamente se a exclusión dos homes da sociedade trae aparellada un mundo mellor para as nenas lectoras. No caso máis extremo, Vallejo (1995: 105) refire a anécdota do director dun centro cultural boliviano ${ }^{10}$ que, ao coñecer o contido das obras de Turín, exclamou: " ¡Libros como estos no deben estar en una biblioteca!".

Co decorrer do tempo, a LIX foi gañando interese como literatura -librándose en boa medida da súa consideración de produto escolar- en España, o que supuxo que moitos mediadores, autoras e críticas promulgasen que as ficcións infantís debían desprenderse, na medida do posíbel, da súa carga moralizante máis evidente. Enténdese neste contexto que a imaxe da colección ideada por Turín se desvalorizara un tanto, como amosa esta enérxica opinión do escritor Emili Teixidor (2000: 12): "Una colección italiana para niñas se llamaba ¡A Favor de las Niñas! Era cuando se precisaban protagonistas y modelos literarios femeninos. Pues bien, $j$ a favor de la infancia, o de la juventud! Lejos de la propaganda".

Porén, os libros de Turín constitúen un punto e a parte na historia da literatura infantil e o tratamento dos xéneros, sendo un novo comezo que moitas instancias seguen valorando moi favorablemente nesta altura. Quizais pola súa pervivencia en moitas bibliografías específicas, quizais como contestación indirecta aos retrocesos que se están a vivir en materia da igualdade (tamén no campo da literatura), os contos que integraban a

${ }^{7}$ A colección tivo a súa plasmación en varios países europeos. No Reino Unido foi publicada por Writers and Readers Cooperative, a partir de 1976. En Francia, a súa publicación correu a cargo de Editions des Femmes e foi acometida a partir de 1978.

${ }^{8}$ Nótese que o nome é compartido non só polo colectivo de mestras anteriormente mencionado, senón tamén pola obra homónima da feminista italiana Elena Gianini Belotti, publicada en 1973, que é a que presumiblemente dá orixe a que a editora de Adela Turín teña o nome que ten.

${ }^{9}$ De feito, a autora do artigo denuncia o sexismo de moitos contos tradicionais, pero as solucións que propón A favor de las niñas -aínda considerándoa unha resposta á maioría de LIX, que discrimina ás cativas, e valorándoa como eliminadora de prexuízos (Rodríguez 1977: 37)- non lle parecen axeitadas polo seu estremismo.

${ }^{10}$ De ascendencia suíza, sinala a autora, suponse que para evidenciar que os prexuízos contra o feminismo non derivan da cultura latinoamericana en que se insire. 
colección orixinal están sendo reeditados, nun formato actualizado, por Kalandraka dende $2012^{11}$. A serie, que tamén hai que entendela na liña editorial de recuperación de álbums clásicos emprendida como liña de acción pola editora, leva o nome da súa creadora, o que tamén indica o grao de coñecemento que perciben que existe sobre a figura de Adela Turín.

\subsection{ALGUNHAS TENTATIVAS DE MA- TERIAL LITERARIO COEDUCATIVO EN LINGUA GALEGA}

Dado que as coleccións coeducativas que se analizarán pertencen ao sistema literario galego, é preciso facer mención aos esforzos realizados neste sentido en Galicia, especialmente durante a década dos 90 -que resulta ser tamén o momento en que se conta xa cunha literatura infantil e xuvenil na que existe unha produción considerable como resultado das angueiras dos anos oitenta. Alén de propostas puntuais de diferentes editoras do país (entre as que por suposto se atopan as obras das autoras antes referenciadas como pioneiras no tratamento igualitario dos sexos e da introdución do feminismo na LIX galega), cómpre resaltar a achega de Ir Indo Edicións a través da colección "O parrulo". A mesma, posta en funcionamento no ano 1990, incluíu tanto traducións de obras referenciais de coeducación (o exemplo máis visible é $A$ derradeira Cincenta de Renata Mathieu ${ }^{12}$ ), como textos que implicitamente apostaban pola coeducación, como podía ser Dona Carme de Manuel Bragado ou as tres obras publicadas por Azucena $\operatorname{Arias}^{13}$, que avogan por algo tan sinxelo -á vez que efectivo- como presentar a protagonistas do mundo animal de ambos sexos ${ }^{14}$. O exemplo máis claro é precisamente o conto rimado titulado $A$ cirurxiá, en que a galiña Cacaracá desenvolve esa profesión curando con acerto a todos os animais que pasan pola súa consulta. Aínda así, é preciso incidir na idea de que a colección non estaba especificamente deseñada como "coeducativa", mais semella evidente que os seus responsables ${ }^{15}$ si tiñan en conta este criterio.

Dende a perspectiva institucional, existiu tamén a tentativa de facer un volume literario con elementos coeducativos. Esta idea materializouse en Furacazolos e Botaborrallas, un texto da autoría de Isabel Fidalgo e ilustracións de Suso Cubeiro, publicado en 1998. O mesmo ten escasa entidade narrativa, presentando unha breve e confusa trama que conta a historia de dous trasgos (macho e femia) que viven nun ático cunha gata e un can e que comparten os quefaceres. Tras comprobar que teñen unha pingueira no teito, demandan a axuda de dous albaneis para amañala, sendo a moza a que se encarga de facelo porque o mozo albanel ten medo. Porén, ela esvara tentando reparar a desfeita e é salvada por Furacazolos, o trasgo macho, mentres o seu compañeiro albanel chora. Ao errático e confuso da historia (na procura dun texto tan igualitario, a autora cae na trapela de transmitir que a muller acaba sempre salvada polo home), cínguese o nulo coidado formal na edición, que esquece a tradición da publicación dos libros infantís en galego e aposta por un volume encadernado en espiral con escaso acerto na tipografía e nos deseños

\footnotetext{
${ }^{11}$ Ata o momento (outubro de 2014) os títulos publicados son Artur e Clementina, Rosa Caramelo, A historia dos bonobos con gafas e Unha feliz catástrofe.

${ }^{12} \mathrm{Na}$ mesma, unha nena -na versión galega chamada Iria- fai concienzudamente as tarefas da casa a seu pai e irmáns ata que un día decide rebelarse e inclúe nas súas labouras diferentes trasnadas, que serán as que lles fagan a eles responsabilizarse da parte de traballo que lles corresponde.

13 Trátase, en concreto, de $A$ cirurxiá (1998), A casa do grilo e a chicharra (2000) ou A cadela e o óso (2001). A autora deste artigo quere agradecer moi especialmente a María Luísa Abad que lle dese a coñecer algunhas das obras da colección "O parrulo".

${ }^{14}$ Unha ollada a textos en que os protagonistas son animais.

${ }^{15}$ Xosé Manuel González Barreiro era o director da colección, mentres que as labouras de coordinación as levaba a cabo Antón Mascato.
} 
que o compoñen. A publicación do Servizo Galego de Igualdade esquece ou descoñece os precedentes na elaboración deste tipo de materiais e acaba xerando un conto de mensaxe polémica e contraditoria, cunha estética propia de principios dos anos setenta. É de supor que, en parte polas características enunciadas, o volume non acadou unha difusión sinalable.

\section{AS NOVAS COLECCIÓNS COEDU- CATIVAS: "CONTOS DA IGUALDADE", "LILA LILALINA" E "A IGUALDADE CONTA"}

Xa no século XXI, como consecuencia dos esforzos levados a cabo por diferentes axentes a prol da igualdade, apóstase pola creación de coleccións coeducativas en galego. A primeira no ámbito da literatura de noso é "Contos da Igualdade" de Baía Edicións, que publica, a partir de $2006^{16}$, cinco volumes -ideados por diferentes autoras- e dirixidos a un público que oscila entre os 3 e os 10 anos e que está promovida polo Servizo Galego da Igualdade. A segunda, seguindo a orde cronolóxica, sería "Lila Lilaina" da desaparecida A Nosa Terra Edicións, con catro volumes escritos e ilustrados por Ana Pillado e concibidos a modo de serie, xa que se adoitan repetir os personaxes. $\mathrm{O}$ público ao que fundamentalmente se dirixe é o prelectorado e o lectorado inicial. Por último, tamén destinada a estas franxas de idade estaría a proposta de Edicións Embora, "A igualdade conta", elaborada por completo por Cristina Justo e Paloma Rodríguez (profesoras universitarias, o que incide no amparo que a colección ten no mundo académico) e con seis títulos ata o momento publicados entre 2010 e 2013.

Todas estas propostas teñen unha serie de características comúns que as encadran, como se verá, dentro dun mesmo tipo de libros para a infancia e a mocidade, que se podería denominar como "obras didácticas" ou "literatura de valores". Se ben se considera que todo texto literario, for para público adulto, for para nenas e mozos, ten unha compoñente educativa, a concepción tradicional -e tamén inicial- da literatura infantil era o seu uso didáctico, é dicir, os libros eran un instrumento non orientado á fantasía e á creatividade, senón que estaban enfocados á transmisión de normas, valores e coñecementos de diverso tipo. En realidade, este tipo de publicacións cumpre unha función idéntica, pois en ocasións -como é o caso de "Lila Lilaina" e "Contos de Igualdade"- chegan a ter un apéndice máis ou menos extenso de actividades que, a modo de reforzo, afondan nos contidos e premisas que se pretende ensinar.

\subsection{CONSIDERACIÓNS DENDE O PUN- TO DE VISTA DA EDUCACIÓN LITE- RARIA}

A pesar deste loubable propósito educativo, se se analizan as coleccións dende a perspectiva da educación literaria, os resultados non son moi alentadores. Por unha banda, o primeiro elemento obxectivo que se pode observar é que a grande maioría dos títulos que as compoñen non foron creados por escritoras profesionais -se é que en Galicia se pode falar dunha "profesionalización" da escritura-, senón que foron encargados a diferentes axentes do sistema aos que se recorreu ad hoc. Isto vencéllase, polo menos en parte, co feito de que nelas non adoita haber unha historia "consistente" dende o punto de vista literario, senón unha trama simple na que se buscan fins morais e non acontecementos singulares que permanezan na mente do lectorado. Por exemplo, na obra Rosa e azul de Ana Pillado ("Lila Lilaina"), o argumento é simple: o avó e a avoa chegan cuns agasallos para o neno e a nena da casa, que resultan ser cadanseu xogo de bufanda e luvas. O do rapaz é azul e o da cativa rosa, ata que deciden cambialos porque se decatan de que a cada un lle gusta a cor que lle tocou ao outro. A máxima que se quere transmitir fica clara: non hai colores máis axeitados para un ou outro xénero.

${ }^{16}$ O último sae en 2010 , polo que parece que a colección está pechada. Inda así, non existe unha certeza absoluta sobre esta cuestión. 
Igualmente, a maioría dos personaxes son absolutamente planos, respondendo a tipos concretos que seguramente non resulten atractivos ou interesantes polo seu marcado maniqueísmo ao lectorado primario ao que van dirixidos. Unha mostra evidente disto podería ser o álbum $A$ urna dos desexos de Cristina Justo e Paloma Rodríguez, que presenta a Clara (unha nena que se chama así por Clara Campoamor) nun día de eleccións, en que vai acompañar a súa nai e a súa avoa a votar ao partido violeta -cada partido ten o nome dunha cor- mentres seu pai cociña, porque non quere participar nos comicios. A trama é un tanto confusa, mais a máxima moral que se quere transmitir é evidente: a igualdade debe chegar e/ou afianzarse tamén no ámbito político. Non por acaso, a nena protagonista acaba por querer ser presidenta.

O único caso que escapa a estas particularidades, entre os quince títulos que conforman as tres coleccións, é o da obra Xela volveuse vampira, da autoría de Fina Casalderrey. $\mathrm{Cu}$ riosamente, trátase do tex to que aborda a cuestión máis delicada: a violencia física contra as mulleres. Porén, o oficio da escritora e a súa particular habilidade para situarse detrás dos ollos das cativas e cativos cunha sensibilidade exquisita, dá lugar á narración máis conseguida, onde si hai unha experiencia literaria elaborada. Así, Xela é a mestra de Breixo, o protagonista, e tanto el como os outros nenos e nenas da clase decátanse de que ultimamente a profesora non ten enerxía para nada e mesmo esqueceu todas as cancións e contos que outrora lles aprendera. Cando aparecen os primeiros moratóns e a actitude da mestra se transforma por completo e se nega mesmo a saír ao patio, a rapazada pensa que se converteu nunha vampira. Finalmente, Breixo, coa axuda dunha trasna, poderá axudar a Xela para que comece a superar a situación. No texto de Casalderrey, apréciase como existe unha experiencia literaria elaborada, que redundará na construción dunha educación literaria real.

O resto de obras non contan con ela, como tampouco sitúan ao público lector ante espazos baleiros, que son os que lle permiten a cooperación interpretativa e a elaboración de significados. Pola contra, a palabra que fai posible a obra artística ten que conter estes espazos (Sánchez Corral 1995). Mais, precisamente, o contido e a linguaxe destas obras aseméllase máis ao da propaganda, pola súa natureza persuasiva.

\subsection{CONSIDERACIÓNS DENDE A IDEN- TIDADE FEMININA}

Se se procura o susbtantivo "identidade" no dicionario da Real Academia Galega, a definición que se fornece é a de "conxunto de características ou elementos que definen a unha persoa ou cousa fronte ás demais, o que fai que sexa recoñecida como tal". Porén, deténdose en todas as personaxes femininas que aparecen nestas obras, resulta complicado establecer cal é a súa identidade, porque en realidade todas responden a un mesmo modelo, que se podería subdividir en dous: o da muller adulta que pode con todo e que se realiza profesionalmente cunha laboura considerada tradicionalmente como non feminina, e o da nena intelixente e activa que, a pesar da súa curta idade, ten unha certa capacidade para romper cos roles de xénero - malia que a sociedade se posicione indicando sempre o camiño contrario. Tomando como exemplo a nai protagonista de Un día de treboada de María de Mata ("Contos da igualdade"), obsérvase a unha muller forte e traballadora que é tractorista e consegue ser quen de axudar a toda a aldea nas tarefas do campo un día de moita chuvia. O seu nome só se coñece contra o final da narración, mais iso non resulta relevante, porque o que é importante verdadeiramente son as accións que realiza. Pola súa banda, en Carlota e o príncipe azul de Ana Pillado ("Lila lilaina"), Carlota non quere baixar do tobogán ata que veña un príncipe rescatala. Non obstante, Lila - protagonista de toda a serie de narracións- descoñece o que fan os príncipes e dille que é moi aburrido esperar sen ningún obxectivo, polo que transforma a actitude da súa compañeira de xogos. Estes feitos, unidos á ausencia da valorización de acción e características tradicionalmente marcadas como femininas polo patriarcado (empatía, coidado, paciencia, timidez), redundan no xurdimento 
dun novo estereotipo: o da supermuller empoderada que absorbeu a meirande parte dos trazos contemplados outrora como propios do xénero masculino. A súa versión infantil, a nena resistente -e polo tanto tamén empoderada-, adoece do mesmo e limita a identificación das lectoras ao fornecerlles, como facían os libros máis conservadores, tan só un modelo de actuación. Onde está a multiplicidade literaria? Por que é necesario este pouso de irrealidade á hora de abordar as identidades femininas dende unha perspectiva coeducadora? Seguramente polo cariz directivo de todos estes textos que, ao final, acaban deixando a idea no lectorado de que só hai unha forma de ser muller ou nena. Porque ao final estas narracións presentan a súa ideoloxía na tona máis superficial, agochan conflitos e coutan a posibilidade de escoller. E cómpre dicilo, que un libro sexa coeducativo non debe ser sinónimo de que un libro sexa aburrido, sen deleite estético e careza de personaxes femininos que, precisamente porque deben escoller, entran en conflito. Porén, nestas coleccións apenas hai escollas, tan só feitos dados.

\section{A XEITO DE CONCLUSIÓN}

A literatura infantil dos anos noventa en diante abriu as aprendizaxes da nena e do neno, fíxoos autónomos na busca da significación das obras, non obstante, este tipo de coleccións avogan -en xeral- por unha visión moi moralizante en que se indica continuamente o que se debe facer, como se debe actuar e mesmo cómo cómpre ser. En realidade, estas coleccións volven promover unha visión puramente escolar da literatura, esquecendo os precedentes anteriores e sen ter en conta as críticas que estes recibiron. Seguramente polo descoñecemento de referentes no tratamento igualitario dos xéneros, como pode ser a colección "A favor de las niñas" de Adela Turín, editoras e autoras volveron cometer erros semellantes, harmonizando agora tamén as identidades das súas protagonistas.
Por isto mesmo, as mediadoras e mediadores de hogano deben contemplar que, se ben estas coleccións son válidas para un uso puramente didáctico (e igualmente loubables dende tal perspectiva), a súa eficacia dende o punto de vista literario cómpre poñela, cando menos, entre parénteses. A gran pregunta volve ser que tipo de literatura infantil se procura, pois como sinalou Juan Cervera (2003): "el cuento se cuenta, pero no se explica, de lo contrario se pierde en eficacia educativa, aunque (...) se gane en eficacia didáctica".

É preciso tamén volver sobre obras literarias de calidade en que as nenas e mozas son protagonistas, cun especial coidado no tratamento dos xéneros, antes de crear textos cuxa única fin sexa marcar pautas de actuación. É evidente que as reivindicacións a prol dunha literatura máis igualitaria que comezaron nos anos 70 non perderon a súa actualidade -especialmente polas regresións en materia de feminismo e de igualdade nos últimos anos-, mais isto ás veces escurece a existencia de textos literarios feministas, doutros que avogan pola igualdade sen posicionarse tan marcadamente e doutros que presentan novas maneiras de ser nenos e homes, fornecendo alternativas tamén para eles. Os avances, que tamén os hai neste eido, deben ser contados e analizados pola crítica, entre outras cousas, para difundilos.

Se na cita de Paul Hazard que principia este artigo o autor poñía de manifesto as dificultades iniciais para que existise unha literatura infantil, cómpre preguntarse se, agora que este campo literario se configurou como un dos máis potentes, os corsés, as correaxes e os xustillos non volveron outravolta, cando menos en certo tipo de libros. A arela das instancias mediadoras debe ser que esas roupaxes continúen sendo flexibles. Se non, o traxe con que estamos vestindo a bagaxe lectora da infancia tan só será unha armadura. Unha armadura que pouco ten que ver coa educación literaria e con todas as aprendizaxes que ofrece a literatura. 


\section{REFERENCIAS BIBLIOGRÁFICAS}

Arias, Azucena (1998): A cirurxiá. Vigo: Ir Indo.

Bragado, Manuel (1990): Dona Carme. Vigo: Ir Indo.

CASAlderrey, Fina (2007): Xela volveuse vampira. A Coruña: Baía Edicións.

Cervera Borrás, Juan (2003): "La literatura infantil, los límites de la didáctica", Biblioteca Virtual Miguel de Cervantes (dispoñíbel en: http://www.cervantesvirtual.com/nd/ark:/59851/ bmen8751).

"Escuela no sexista", Colectivo (1984): “Algunos libros para continuar", Cuadernos de Pedagogía 118 [s. p.].

Folguera, Pilar (2007): "De la transición política a la paridad", en P. Folguera (ed.), El feminismo en España. Dos siglos de historia. Madrid: Editorial Pablo Iglesias, pp. 157-199.

Gárate, Arantza (1997): “Niños, niñas y libros”, Cuadernos de Literatura Infantil y Juvenil (CLIJ) 95, pp. 7-17.

Gastaudi, Paz (1983): “Cuento”. Colaboración s/n (Monográfico "Escuela y roles sexuales” [s. p.].

Justo, Cristina e Paloma Rodríguez (2010): A urna dos desexos. Ferrol: Edicións Embora.

MATA, María de (2006): Un día de treboada. A Coruña: Baía Edicións.

Mathieu, Renata (1992): A derradeira Cincenta. Vigo: Ir Indo.

Pena Presas, Montse (2012): “As imaxes femininas na narrativa infantil e xuvenil galega: dos roles tradicionais á novela feminista (1975-1985)", Madrygal. Revista de Estudios Gallegos 15, pp. 107-117.

Pillado, Ana (2009): Carlota e o príncipe azul. Vigo: A Nosa Terra.

Pillado, Ana (2008): Rosa e azul. Vigo: A Nosa Terra.

RodríGuEz, Armonía (1977): “Ideología sexista y literatura infantil”, Cuadernos de Pedagogía 36, pp. 36-37.

SANCHEZ CORRAL, Luis (1995): Literatura infantil y lenguaje literario. Barcelona: Paidós.

VAllejo de Bolívar, Gaby (1995): "La revolución de las niñas. Aproximación a la literatura infantil de Latinoamérica", en VV.AA, Memoria. 24 Congreso Internacional del Ibby de Literatura Infantil y Juvenil. (Sevilla 11-15 de octubre de 1994). Madrid: Organización Española del Libro Infantil y Juvenil, pp. 102-105. 